\title{
Development and implementation of a Telenephrology dashboard for active surveillance of kidney disease: a quality improvement project
}

Melissa L. Swee ${ }^{1,2^{*}}$ (D, M. Lee Sanders ${ }^{1,2}$, Kantima Phisitkul ${ }^{1,2}$, George Bailey $^{2}$, Angie Thumann $^{2}$, Nikki Neuzil ${ }^{2}$, Bharat Kumar ${ }^{3}$, Amy M. J. O'Shea ${ }^{2,4}$ and Bradley S. Dixon ${ }^{1,2}$

\begin{abstract}
Background: Kidney disease accounts for more than 49 billion dollars in healthcare expenditures annually. Early detection and intervention may reduce the burden of disease. We describe a quality improvement project to develop a telenephrology dashboard that proactively monitors kidney disease.

Methods: One hundred eighty-four thousands Veterans within the lowa City Veterans Affairs Health Care System were eligible for telenephrology consultation. The dashboard accessed the charts of 53,085 Veterans at risk for kidney disease. We utilized Lean-Six Sigma tools and principles and the Define-Measure-Analyze-Improve-Control Framework to develop and deploy a telenephrology dashboard in 4 community-based outpatient clinics (CBOCs). The primary measure was the number of days to complete consultation. Secondary measures included number of electronic consultations per month, distance and cost of Veteran travel saved, and number of steps for completion of consult.

Results: The data of 1384 Veterans at the 4 CBOCs were analyzed by the telenephrology dashboard, of which 459 generated telenephrology consults. The number of days to complete any type of consultation was unchanged (48.9 days in 2019, compared to 41.6 days in 2017). The average Veteran saved between $\$ 21.60$ to $\$ 63.90$ per trip to lowa City. Between March 2019 and August 2019, there were 27.3 telenephrology consults per month. The number of steps needed to complete the consult request was decreased from 13 to 9.

Conclusions: Utilization of the telenephrology dashboard system contributed to an increase in consultations completed through electronic means without decreasing face-to-face consults. Electronic consults now outnumber traditional face-to-face consultations at our institution. Telenephrology consultation improved early detection and identification of kidney disease and saved time and costs for Veterans in travel, but did not decrease the average number of days to complete consultation requests.
\end{abstract}

Keywords: Kidney diseases, Quality improvement, Telemedicine, Rural health

\footnotetext{
* Correspondence: Melissa-Swee@Ulowa.edu

'Division of Nephrology, University of lowa Hospitals and Clinics, 200

Hawkins Drive, lowa City, IA 52245, USA

${ }^{2}$ lowa City Veterans Affairs Health Care System, lowa City, USA

Full list of author information is available at the end of the article
}

(c) The Author(s). 2020 Open Access This article is licensed under a Creative Commons Attribution 4.0 International License, which permits use, sharing, adaptation, distribution and reproduction in any medium or format, as long as you give appropriate credit to the original author(s) and the source, provide a link to the Creative Commons licence, and indicate if changes were made. The images or other third party material in this article are included in the article's Creative Commons licence, unless indicated otherwise in a credit line to the material. If material is not included in the article's Creative Commons licence and your intended use is not permitted by statutory regulation or exceeds the permitted use, you will need to obtain permission directly from the copyright holder. To view a copy of this licence, visit http://creativecommons.org/licenses/by/4.0/ The Creative Commons Public Domain Dedication waiver (http://creativecommons.org/publicdomain/zero/1.0/) applies to the data made available in this article, unless otherwise stated in a credit line to the data. 


\section{Background}

Kidney disease is a major contributor to disease burden in the United States, affecting 30 million individuals [1], and accounting for more than 49 billion dollars per year in healthcare costs in the Medicare population alone [2]. Early detection of at-risk patients in primary care clinics and timely consultation with kidney specialists may potentially reduce this burden [3]. However, the lack of efficient coordination between primary care and nephrology clinics often leads to delays in care and missed opportunities for early intervention [4]. The global nephrology workforce shortage further exacerbates the problem and highlights the need to develop newer tools to more efficiently evaluate and care for patients with early signs of kidney disease [5].

The development and utilization of dashboards may help to address this problem. In recent years, dashboards have been developed in several settings to pro-actively identify and manage conditions, including kidney disease [6]. Studies suggest that dashboards may help to improve adherence to quality guidelines and improve patient outcomes [7]. Because the practice of nephrology is largely dependent upon monitoring of laboratory results and vital signs, development of a dashboard for kidney diseases is an appealing quality improvement approach [8].

The Iowa City Veterans Affairs (VA) Health Care System is a member of the Veterans Affairs Midwest Health Care Network that serves more than 184,000 Veterans living in 50 counties spread throughout the mostly rural areas of Eastern Iowa, Western Illinois, and Northern Missouri. While the hospital and specialized clinics, including Nephrology, are headquartered in Iowa City, there are also 10 community-based outpatient clinics (CBOCs) in Iowa and Illinois that deliver primary care [9]. When specialist services are required, patients are either referred to the clinics in Iowa City or receive care in the community outside of the VA system. This often poses problems for coordination of care between primary care practitioners and nephrologists. This quality improvement initiative aims to facilitate such coordination through the development of a dashboard.

\section{Methods}

This study was submitted to the Institutional Review Board at the Iowa City Veterans Affairs Health Care System. As a Quality Improvement initiative, it was exempt from full review.

We utilized Lean Six Sigma principles and tools as well as the Define-Measure-Analyze-Improve-Control (DMAI C) Framework to structure our intervention (Table 1). Lean Six Sigma is a well-validated set of methods to systematically engage in quality improvement, and the DMAI $\mathrm{C}$ Framework has been utilized in multiple healthcare settings to effect successful changes in practice $[10,11]$.

\section{Study sites and participants}

This initiative took place at $4 \mathrm{CBOCs}$ within the state of Iowa: Ottumwa, Quincy, Galesburg, and Dubuque. These 4 CBOC's have 23 primary care practitioners (PCPs), of which 9 participated in the quality improvement project. These 9 PCPs serve approximately 9000 patients, of which 93\% live in rural or very rural areas. Like in most VA settings, the majority of patients are male (in this case, 97.4\%). The telenephrology nurse coordinator screened patients to determine eligibility for telenephrology consultation, based on whether they had chronic kidney disease Stage $3 \mathrm{~b}$ or above (eGFR < 45), acute kidney injury, hematuria, or proteinuria. Patients who were already seeing a non-VA nephrologist were excluded, and those that were seeing a VA nephrologist were screened to determine if there was a new complication that warranted a telenephrology consultation.

\section{Defining and measuring the problem}

At the start of this initiative, we drafted a project charter outlining the aims, scope, participants, outcomes, and benchmarks for the project. A multidisciplinary core team of two nephrologists (KP and MLS), two PCPs (DC and $\mathrm{MH})$, a quality improvement scholar (MS), two nephrology nurse coordinators (AT and NN), one PCP nurse coordinator (TB), a health informatics expert (GB), and the chief of medical service (BSD) was assembled. PCPs and nephrologists were consulted at every step of drafting the project charter and developing protocols.

The primary impact measure was the number of days between the PCP entering an order for any type of nephrology consult and the nephrologist completing a consult note. In addition to traditional face-to-face encounters, we also included e-consults, where PCPs enter a consult order and nephrologists review the order without contacting the patient, and Clinical Video Telehealth (CVT) appointments, where encounters between nephrologists and patients are conducted through video conferencing technology. Administrative data in the three months prior to the initiation of the project were used to determine the baseline, i.e. status of clinic operations prior to the intervention.

Secondary measures included the number of telenephrology consults and the amount and cost of travel per Veteran. These were obtained through administrative data and the electronic health record. Baseline operations were also documented through the creation of a process map (Fig. 1). MS, AT, and NN followed and documented the individual steps by which a patient is referred to nephrology clinic. This process map depicts the way in which patients with kidney disease come into contact with nephrologists.

\section{Analysis of data}

We obtained data from three major sources: [1] the electronic health record, [2] administrative data, and [3] transcripts of group interviews. 
Table 1 DMAIC (Define-Measure-Analyze-Improve-Control) Framework

\begin{tabular}{|c|c|c|}
\hline & Element of each step & Actions Performed by Core Investigators \\
\hline \multirow[t]{7}{*}{ Define } & Problem statement & $\begin{array}{l}\text { Project Charter was drafted, including a problem statement that articulated the background, } \\
\text { specific needs, and aims of the project }\end{array}$ \\
\hline & Goal statement & $\begin{array}{l}\text { Articulated in the Charter: "Decrease number of days between the PCP entering an order for } \\
\text { any type of nephrology consult and the nephrologist completing a consult note from } 48.9 \\
\text { days to } 30 \text { days, by August 2019." }\end{array}$ \\
\hline & Project scope & $\begin{array}{l}\text { Articulated in the Charter: "This Lean Six Sigma project will take place } 360 \text { days from start to } \\
\text { validated solutions" }\end{array}$ \\
\hline & Identification of project sponsor & The Chief of Medical Services was identified and designed as the project sponsor \\
\hline & Identification of process owner & The telenephrology Case Manager was identified and designated as the process owner \\
\hline & Primary impact measure & $\begin{array}{l}\text { Articulated in the Charter: "Number of days between primary care practitioner entering a } \\
\text { consult and nephrologist performing chart review" }\end{array}$ \\
\hline & Secondary impact measures & $\begin{array}{l}\text { Travel time and costs saved by Veterans } \\
\text { Number of telenephrology consults generated }\end{array}$ \\
\hline \multirow[t]{2}{*}{ Measure } & Baseline operations & $\begin{array}{l}\text { Chart review determined baseline number of days to completion of nephrology consultation } \\
\text { Pre-Intervention Process Map }\end{array}$ \\
\hline & Impact data & Project charter updated regularly based on performance \\
\hline \multirow[t]{2}{*}{ Analyze } & Process mapping & $\begin{array}{l}\text { Current process map from PCP entry of lab order to completion of consult order is shown } \\
\text { in Fig. } 2\end{array}$ \\
\hline & Voice of the customer & $\begin{array}{l}\text { Veterans, PCPs, and Nephrology clinical staff (practitioners and case managers) interviewed } \\
\text { Point-of-care observations performed }\end{array}$ \\
\hline \multirow[t]{3}{*}{ Improve } & Future state maps & $\begin{array}{l}\text { Future state map from PCP entry of lab order to completion of consult order is shown in } \\
\text { Fig. } 2\end{array}$ \\
\hline & Plan-Do-Study-Act cycles & Five PDSA cycles were performed \\
\hline & Pilot results & Gaps between predicted and actual performance analyzed \\
\hline \multirow[t]{3}{*}{ Control } & Development of a control plan & $\begin{array}{l}\text { A control plan was drafted to summarize the process and take steps to ensure that the level } \\
\text { of improvement is maintained and sustained }\end{array}$ \\
\hline & Impact summary & $\begin{array}{l}\text { A one-page impact summary was drafted with simplified language and diagrams for } \\
\text { dissemination within the institution }\end{array}$ \\
\hline & Recognition of work accomplished & $\begin{array}{l}\text { Results of quality improvement project disseminated locally at institutional grand rounds } \\
\text { and nationally at annual conferences } \\
\text { Celebration of short-term wins }\end{array}$ \\
\hline
\end{tabular}

The Quality Improvement Team used the DMAIC Framework to guide the intervention

The electronic health record was used to obtain patient data, including serum creatinine, estimated glomerular filtration rate (eGFR), urine blood, urine proteinto-creatinine ratio, urine microalbumin, and systolic blood pressure (SBP).

Administrative data were collected for certain outcomes, such as the number of days to complete the consult, demographic profiles of patients (location, age, sex, and stated ethnicity) and number of new face-to-face, electronic, and telenephrology consults.

Lastly, we conducted interviews with PCPs, nephrologists, case managers, and Veterans, which were transcribed and analyzed by MS and AT.

\section{Voice of the customer}

The investigative team identified a set of four key stakeholders: PCPs, nephrologists, clinic case managers, and Veterans. Throughout each step of the process, we consulted with the four key stakeholders. Three open-ended questions were asked at each of the interviews: [1] what are your overall thoughts about the current status of the program? [2] how they would change the program? And [3] is the program improving care for Veterans? Group interviews, conducted by BD and AT via video conferencing, with PCPs $(n=9)$, nephrologists $(n=4)$, and clinical case managers $(n=9)$ revealed three themes: [1] delay in getting patients to clinic, [2] concerns about increased workload, and [3] concerns about losing autonomy.

With regards to Veterans, individual interviews were conducted by AT. Veterans voiced frustration at delays in coordinating care and in travel to Iowa City for specialty consultation.

\section{Process mapping}

Based on these insights, the investigative team examined the process map to identify areas for improvement and drafted a future state map (Fig. 1). Of the 13 steps leading to one of two outcomes, there were 6 steps that were deemed to be non-value added, and only 1 non-valueadded step was deemed necessary. This enabled the 


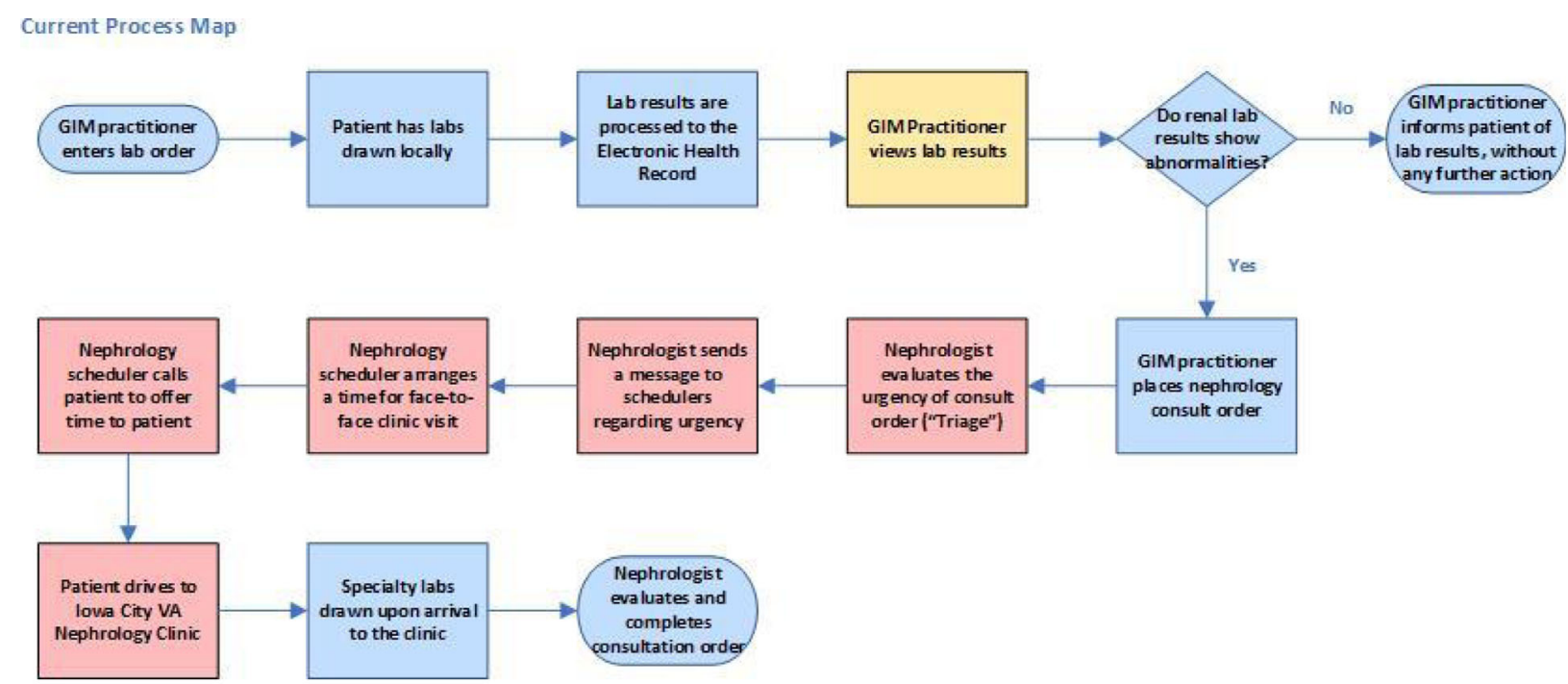

Future State Map

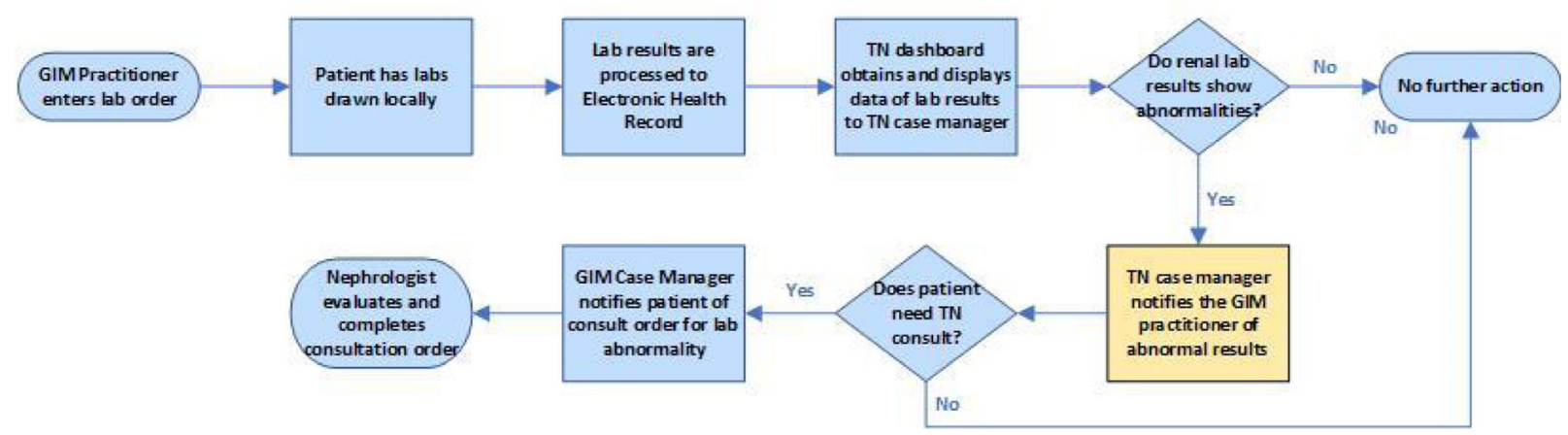

Current process and future state maps were constructed. The current process map revealed 5 non-valueadded unnecessary steps (shaded red) and 1 non-value added necessary step (shaded orange). These were eliminated as much as possible in the future state map.

Fig. 1 Current Process Map \& Future State Map

team to focus on developing approaches and solutions that would reduce or eliminate these steps altogether, and therefore, streamline nephrology care into PCP clinics.

\section{Improvement and refinement of processes Future state maps}

These efforts culminated in the development of a future state map composed of 9 steps leading to one of two outcomes: consultation or no consultation. All six nonvalue-added steps from the current state map were eliminated, but one non-value-added step was introduced in the future state map.

\section{Plan-do-study-act cycles}

We structured our improvement phase into five PlanDo-Study-Act (PDSA) cycles: [1] dashboard design and development, [2] deployment at the Ottumwa CBOC, [3] refinement of parameters for Acute Kidney Injury (AKI), [4] prioritization of subgroups for consultation, and [5] full deployment at the 4 CBOC's (Fig. 2).

Cycle 1: dashboard design and development The dashboard was developed using an iterative process that cycled through [1] collection of user requirements, [2] development of dashboard prototypes, and [3] evaluation of the prototypes. First, the six individuals who would use the dashboard (MS, MLS, KP, AT, GB, and BD) were 


\begin{tabular}{|c|c|c|c|c|c|c|}
\hline & & $\begin{array}{l}\text { Cycle 1: Dashboard } \\
\text { Creation }\end{array}$ & $\begin{array}{l}\text { Cycle 2: Deployment at } \\
\text { Ottumwa CBOC }\end{array}$ & $\begin{array}{l}\text { Cycle 3: Refinement of } \\
\text { Parameters for AKI }\end{array}$ & $\begin{array}{l}\text { Cycle 4: Prioritization } \\
\text { of Subgroups for } \\
\text { Consultation }\end{array}$ & $\begin{array}{l}\text { Cycle 5: Full } \\
\text { Deployment at } 4 \\
\text { CBOC's }\end{array}$ \\
\hline & & October 2017 - March 2018 & April 2018 - June 2018 & June 2018 & June 2018 & July 2018 - Current \\
\hline \multirow{3}{*}{ Plan } & Hypotheses & $\begin{array}{l}\text { A telenephrology (TN) } \\
\text { dashboard can be created based } \\
\text { on user preferences for features }\end{array}$ & $\begin{array}{l}\text { Deployment of the TN } \\
\text { dashboard at Ottumwa will } \\
\text { enable at least } 15 \% \text { of } \\
\text { dashboard hits to be } \\
\text { converted into TN consults }\end{array}$ & $\begin{array}{l}\text { Changing the parameters for } \\
\text { triggering TN consult for AKI } \\
\text { will lead to a smaller pool of } \\
\text { Veterans who are more likely } \\
\text { to require intervention }\end{array}$ & $\begin{array}{l}\text { Prioritizing younger veterans at } \\
\text { greater risk of kidney disease } \\
\text { is more likely to generate } \\
\text { specific recommendations } \\
\text { from TN consultation }\end{array}$ & $\begin{array}{l}\text { Implementation of the TN } \\
\text { dashboard will help to } \\
\text { increase the percentage of } \\
\text { consults completed within } 30 \\
\text { days to } 80 \%\end{array}$ \\
\hline & Intervention Plan & $\begin{array}{l}\text { Kano Evaluation Model to } \\
\text { characterize features }\end{array}$ & \begin{tabular}{|l} 
To utilize the dashboard to \\
collect data from patients at \\
Ottumwa through the EHR
\end{tabular} & $\begin{array}{l}\text { Delphi method among the } \\
\text { nephrologists to define } \\
\text { parameters for AKI }\end{array}$ & $\begin{array}{l}\text { Stratify patients by age and risk } \\
\text { of progression of CKD }\end{array}$ & $\begin{array}{l}\text { To implement the TN dashboard } \\
\text { at } 4 \text { CBOC's }\end{array}$ \\
\hline & Data Collection Plan & $\begin{array}{l}\text { Brainstorm potential features } \\
\text { for the dashboard } \\
\text { Solicit preferences for desired } \\
\text { features } \\
\text { Apply Kano Evaluation Model }\end{array}$ & $\begin{array}{l}\text { Solicit feedback from PCPs via } \\
\text { the voice of customer } \\
\text { Observe practitioner workflow } \\
\text { Conduct chart reviews }\end{array}$ & $\begin{array}{l}\text { Use Voice of the Customer for } \\
\text { both PCPs and nephrologists } \\
\text { Conduct chart reviews }\end{array}$ & $\begin{array}{l}\text { Use Voice of the Customer for } \\
\text { both PCPs and nephrologists } \\
\text { Conduct chart reviews }\end{array}$ & $\begin{array}{l}\text { Solicit feedback from PCPs via } \\
\text { voice of the customer } \\
\text { Observe practitioner workflow } \\
\text { Conduct chart reviews }\end{array}$ \\
\hline Do & Intervention & Develop a TN dashboard & $\begin{array}{l}\text { Deployment of the TN } \\
\text { dashboard at the Ottumwa } \\
\text { CBOC }\end{array}$ & $\begin{array}{l}\text { Changed the protocol for } \\
\text { triggering TN consult for AKI }\end{array}$ & $\begin{array}{l}\text { Patients in the youngest quartile } \\
\text { in age and with the steepest } \\
\text { decline in eGFR were } \\
\text { prioritized for consultation }\end{array}$ & $\begin{array}{l}\text { Implementation of the TN } \\
\text { dashboard at the } 4 \text { CBOCs } \\
\text { (Ottumwa, Galesburg, Quincy, } \\
\text { and Dubuque) }\end{array}$ \\
\hline Study & $\begin{array}{l}\text { Data Summary \& } \\
\text { Analysis }\end{array}$ & $\begin{array}{l}\text { Dashboard captures data from } \\
53,085 \text { Veterans in the lowa } \\
\text { City VA Health Care System } \\
11,790 \text { Veterans }(22.2 \%) \text { have } \\
\text { evidence of Kidney Disease }\end{array}$ & $\begin{array}{l}\text { The data of } 298 \text { Veterans were } \\
\text { reviewed via the TN } \\
\text { dashboard, of which 50 TN } \\
\text { consults were conducted } \\
(16.8 \%) \text {. }\end{array}$ & $\begin{array}{l}\text { During this time period, AKI's } \\
\text { eligible for TN consultation } \\
\text { reduced from } 251 \text { to } 53 .\end{array}$ & $\begin{array}{l}\text { Veterans with projected } \\
\text { progression to End-Stage Kidney } \\
\text { Disease within } 5 \text { years were } \\
\text { more likely to need a TN consult }\end{array}$ & $\begin{array}{l}\text { The data of } 1384 \text { Veterans } \\
\text { were reviewed via the TN } \\
\text { dashboard, of which } 459 \\
\text { generated TN consults } \\
(33.2 \%)\end{array}$ \\
\hline \multirow[t]{2}{*}{ Act } & $\begin{array}{c}\text { Summarize \& Document } \\
\text { Findings }\end{array}$ & $\begin{array}{l}4 \text { 'Must-Be' features include: } \\
\text { (1) Data tables } \\
\text { (2) Graph display for CKD } \\
\text { (3) CKD Progression Modeling } \\
\text { (4) Color to mark indicators } \\
\text { 3 'Attractive' features include: } \\
\text { (1) Filtering of values } \\
\text { (2) Sorting lab values } \\
\text { (3) Drill down events by date } \\
\end{array}$ & $\begin{array}{l}\text { PCPs voice: } \\
\text { Appreciation for pro-active } \\
\text { stance regarding kidney } \\
\text { disease } \\
\text { Concerns about losing } \\
\text { autonomy } \\
\text { Nephrologists and PCPs voice } \\
\text { concerns about increased } \\
\text { workload }\end{array}$ & \begin{tabular}{l|} 
Nephrologists noted that the \\
volume of TN consults due to \\
potential AKI decreased. \\
However, the number of TN \\
consults remained stable. \\
These patients were more likely \\
to meet the definition of AKI per \\
KDIGO.
\end{tabular} & $\begin{array}{l}\text { Nephrologists and PCPs noted } \\
\text { that TN consults appeared more } \\
\text { likely to catch those that were } \\
\text { at greatest risk for CKD } \\
\text { progression. } \\
\text { Although younger age was } \\
\text { prioritized, Veterans of all ages } \\
\text { were eligible for TN consult. }\end{array}$ & $\begin{array}{l}\text { With a greater focus on patients } \\
\text { most at risk for kidney } \\
\text { disease, percentage of TN } \\
\text { eligible consults being } \\
\text { converted into TN consults } \\
\text { increased from } 16.8 \% \text { in } \\
\text { Ottumwa only to } 33.2 \% \text { in all } \\
4 \text { CBOCs. }\end{array}$ \\
\hline & Define Next Steps & $\begin{array}{l}\text { Deployment of the TN } \\
\text { dashboard into a pilot site }\end{array}$ & Refine definitions of AKI & \begin{tabular}{|l}
$\begin{array}{l}\text { Prioritization of subgroups for } \\
\text { consultation }\end{array}$ \\
\end{tabular} & Implementation at 4 CBOC's & \begin{tabular}{|l} 
Deployment throughout the \\
entire lowa City VA Health Care \\
System
\end{tabular} \\
\hline \multicolumn{7}{|c|}{ Five PDSA Cycles were undertaken by the Quality Improvement team. } \\
\hline \multicolumn{7}{|c|}{ Fig. 2 Plan-Do-Study-Act Cycles } \\
\hline
\end{tabular}

assembled to collectively brainstorm potential dashboard features, leading to a list of 8 proposed features.

To better evaluate priorities for development and evaluation, the quality improvement team used the Kano evaluation model to better categorize features as 'MustHave,' 'Attractive,' 'Indifferent,' 'Questionable,' 'Reverse,' or 'One-Dimensional' (Fig. 3) [12]. Due to the small sample size of users and high degree of agreement, further calculation of satisfaction and dissatisfaction coefficients were not deemed necessary.

'Must-Have' features included data tables for displaying serum creatinine, urine blood, and urine protein, graphs for kidney function over time, incorporation of prediction models for development of CKD, and use of color to mark indicators. 'Attractive' features included filtering of values based on user selection, sorting lab values and ability to drill down to specific events in time. One 'Indifferent' feature was identified: customization of views based on user, and one 'Reverse' feature was noted: automatic notifications of lab changes to users.

The 'Must-Have' and 'Attractive' features were incorporated into draft versions of the dashboard. Incorporation of the 'Indifferent' feature was reserved as an option for the future but there was no demand for its subsequent incorporation.

Cycle 2: implementation - pilot site We piloted the dashboard at the Ottumwa $\mathrm{CBOC}$, the most rural of the
CBOCs (97.3\%), for 3 months. We utilized point-of-care observations to ensure that the dashboard was working effectively and without technical problems. After 12 weeks, we reviewed the data and conducted group interviews with the nephrologists, PCPs, and case managers to identify areas of further improvement. The large volume of telenephrology requests suggested a need to refine parameters for AKI and drove the next PDSA cycle.

Cycle 3: refinement of parameters for AKI Because $16.8 \%$ of dashboard hits resulted in telenephrology consults, the nephrologists and PCPs were concerned that the dashboard was too sensitive in picking up changes in eGFR. Therefore, the quality improvement team used the Delphi method to refine the parameters for AKI, from values of predicted eGFR below the confidence interval for the 95th percentile to a $70 \%$ prediction interval. This reduced the number of dashboard notifications for AKI from 251 to 53.

Cycle 4: prioritization of subgroups for Telenephrology consultation Similarly, due to the high volume of dashboard hits, the quality improvement team sought to prioritize those who would theoretically obtain the greatest benefit from early telenephrology consultation. Veterans with projected progression to end-stage kidney disease within 5 years, and those whose age $<85$ were prioritized, although all patients, regardless of age and 


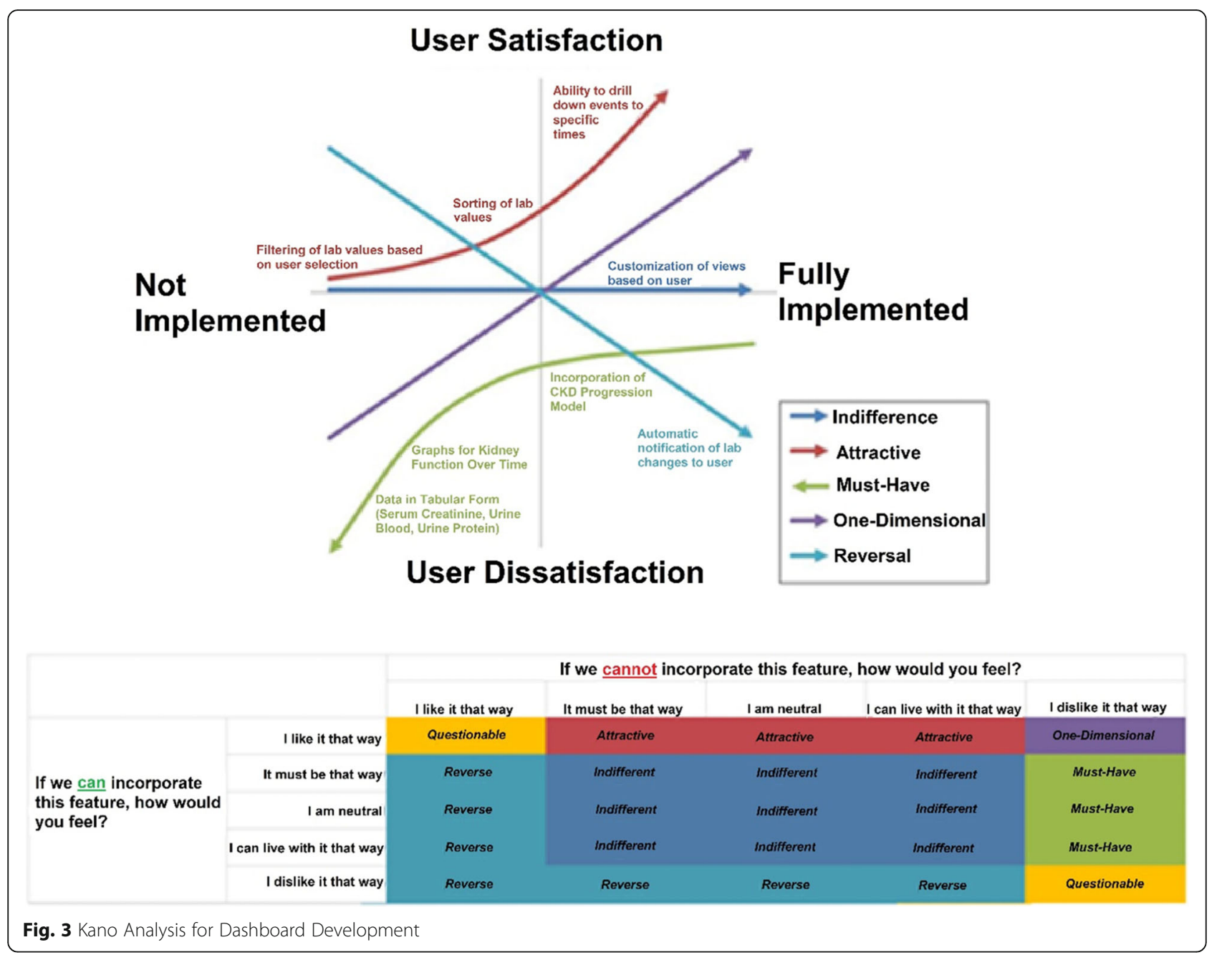

risk of end-stage kidney disease were evaluated for possible telenephrology consultation. This change in workflow did not objectively change the number of eligible consults but rather facilitated triage of consults when volume was high.

Cycle 5: implementation at multiple sites At month 10 , the team began to sequentially expand the number of sites from 1 to 4 , while continuing to collect data on the primary and secondary outcomes. A major concern was increasing the yield of the dashboard so that there was appropriate sensitivity of the telenephrology dashboard for generating telenephrology consults. The addition of new PCPs at other sites also provided opportunities to explore how the program can expand the scope to all 10 CBOCs within the Iowa City VA Health Care System.

\section{Control plan}

In order to build on these successes, the team composed a control and sustainability plan. This control and sustainability plan outlined how the project would continue to evolve beyond the initial 12 months. This included celebration of the short-term wins and dissemination of our data. Additionally, we derived protocols for sustaining telenephrology consultations for nephrologists and case managers (Supplement).

\section{Results}

\section{Dashboard development}

Based on the results of the Kano Analysis, GB developed the telenephrology dashboard software. The 'Attractive' and 'Must-Have' features were incorporated, as shown in Fig. 4. After two iterations, the dashboard was finalized and ready for use on March 2018. Since that time, the dashboard has been accessed daily, principally by the telenephrology case manager (AT).

\section{Process measures}

We identified 6 steps that were non-value-added, of which only 1 was necessary. Based on these, we constructed a future state map and worked towards its realization. 


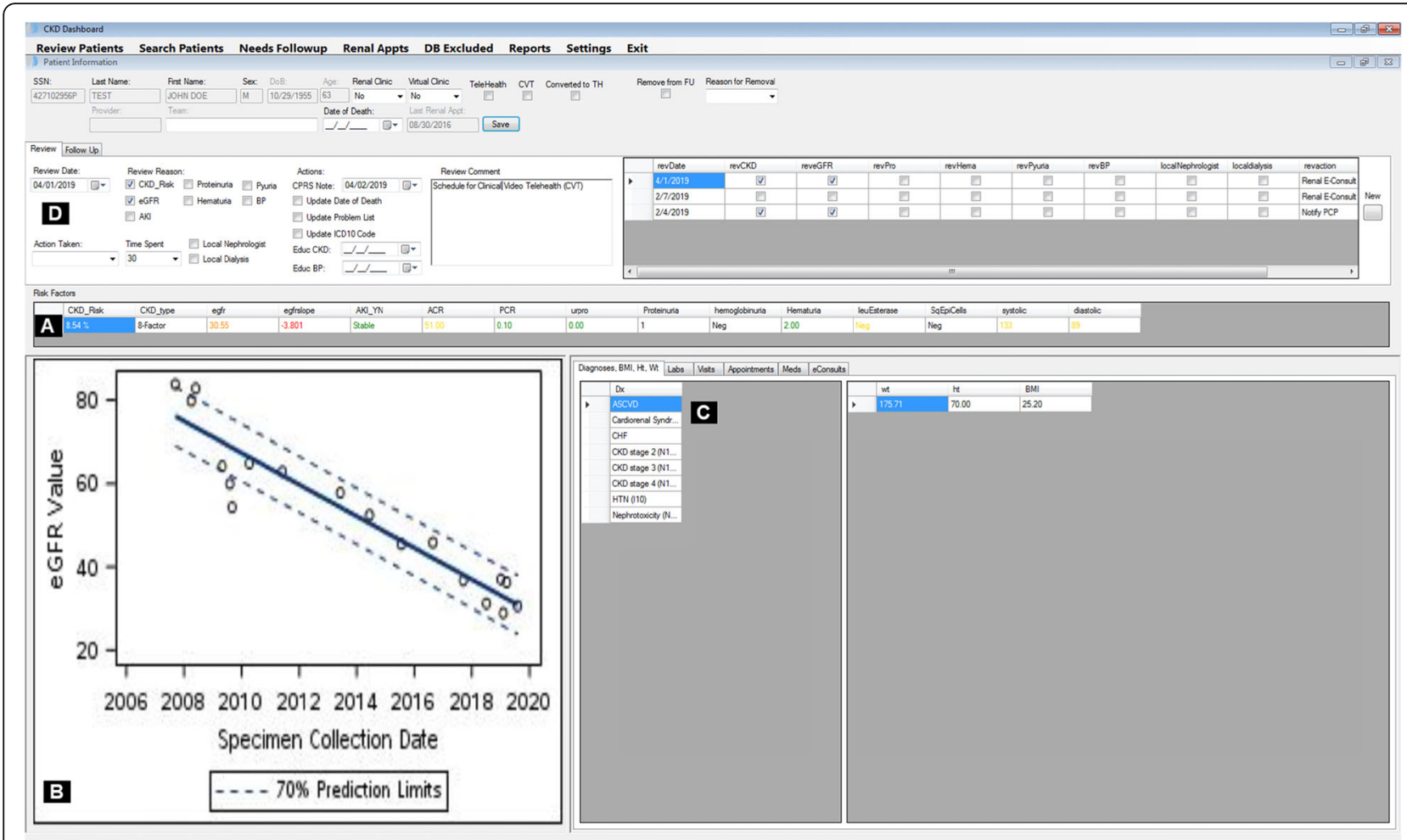

Fig. 4 Dashboard Snapshot

The future state map reduces the number of steps for completion of consultation from 13 to 9 . Notable steps that were eliminated included triage by a nephrologist, scheduling the patient, and Veteran travel to the Iowa City nephrology clinic.

\section{Primary outcome}

Throughout the project, we continued to look at the number of days to completing the consultation request for all face-to-face, electronic, and telenephrology consult orders. There was a change in average time from 41.6 days in 2017 to 28.6 days in 2018 and 48.9 days in 2019 (to July 2019), but these changes were not statistically significant $(p=0.57)$.

\section{Secondary outcomes \\ Veteran travel time and cost}

We saved 47,718 miles of travel for the 459 Veterans in total (mean: 108 miles; median: 100 miles). This amounted to $\$ 21.60$ to $\$ 63.90$ saved per Veteran, depending on the formula used by the Internal Revenue Service to calculate standardized miles.

\section{Telenephrology consultations}

We tracked the numbers of telenephrology consults per month over the course of the 21 months. As Fig. 5 illustrates, the number of telenephrology and other electronic consultation methods has consistently outpaced traditional face-to-face consultation since March 2018, when the team started to utilize the dashboard. Since that time, the system has been largely in control with special cause variation in four of these months. In all of these cases, the number of such electronic consultations has actually exceeded the upper control limit. As of July 2019, the majority of these electronic consultations are now telenephrology consults (55.7\%). Over the last six months of the project (March to August 2019), the average number of consults was 27.3 per month.

\section{Discussion}

Multiple lines of evidence suggest that early detection and management of kidney disease can help to guide more appropriate preventative care, prevent the onset of end-stage kidney disease, and possibly lower healthcare costs $[13,14]$. This quality improvement project helps to address this challenge through the creation of a dashboard for telenephrology consultation. Our experience has important implications for both PCPs and nephrologists as healthcare systems are pressed to improve value and minimizing waste.

First and foremost, we demonstrated how complex healthcare systems can directly integrate nephrologist care into primary care clinics in a way that is dynamic, synergistic, and responsive. There have been trends in the modern American healthcare system towards increasing specialization and separation of nephrologists from 


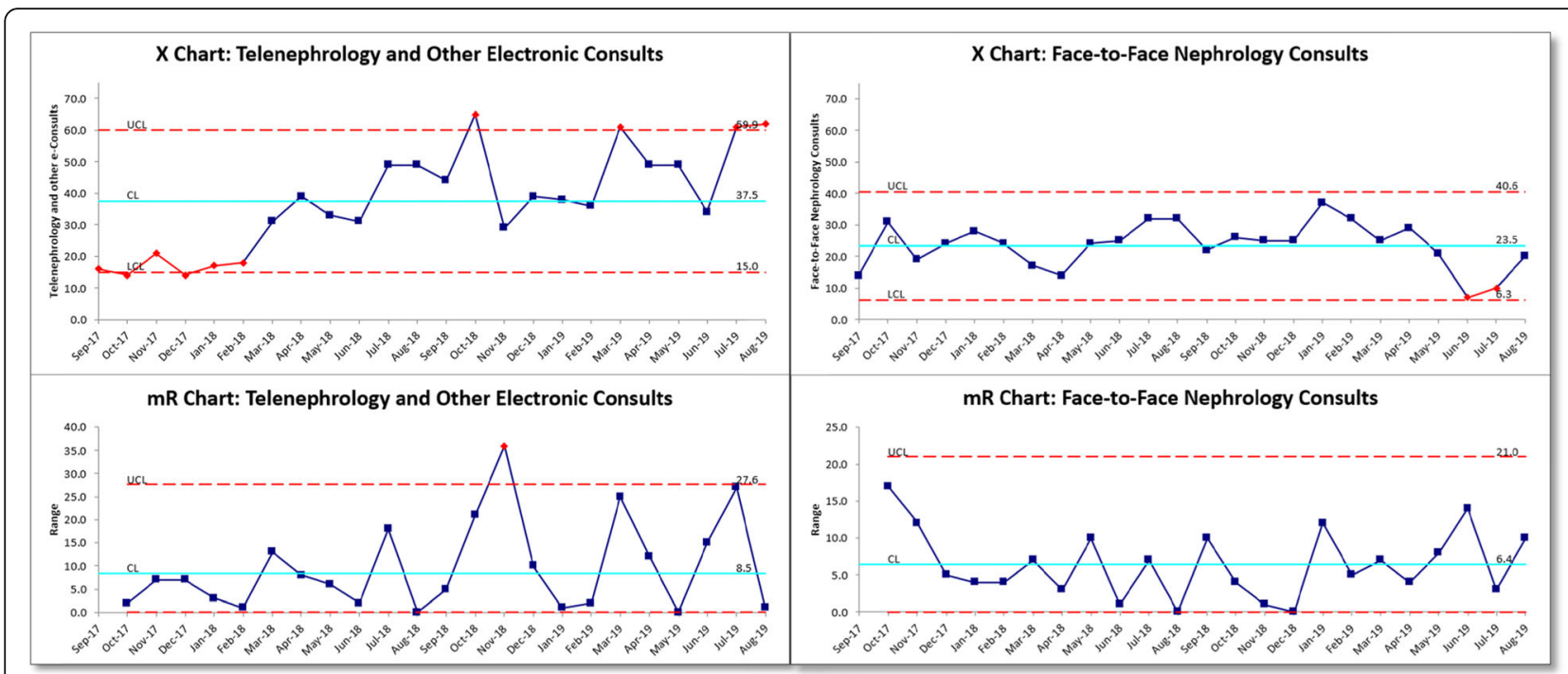

Fig. 5 Run Chart (XmR) of Nephrology Consults

primary care. This separation poses a set of challenges for patients that may lead to delays in obtaining care $[15,16]$. The collaborative process between nephrologists and PCPs that led to the creation of this dashboard is an example of how technology and quality improvement methodologies can be employed to offset the adverse effects of increasing specialization.

Secondly, we have developed a simple, scalable, and flexible dashboard system to monitor kidney disease among patients receiving primary care in the Iowa City Veterans Affairs healthcare system. Dashboards have long been promoted as a means to monitor conditions and diseases, but the quality of a dashboard depends largely upon usability. By using a systematic method to evaluate user needs and desires, we have created a program that is more likely to be integrated into the clinical environment and associated workflows. As the program grows, this systematic method can be employed once again for its redesign.

Thirdly, we have developed software to engage in proactive surveillance of kidney health. The quality improvement team discovered that the dashboard was initially too sensitive for acute kidney injury to be a meaningful instrument for early detection and intervention. Rather, it required refinement of parameters in order to prioritize those who would gain the most benefit from early detection, monitoring, and intervention.

\section{Lessons learned for other institutions}

We have been able to successfully implement this telenephrology consult system using the dashboard tool described above. Our investigative team has gleaned several insights from our experience that may be informative for other institutions aiming to develop similar dashboards and telenephrology consult systems.
Most importantly, it is vital to develop a multidisciplinary team that represents the interests of various stakeholders. In our case, we ensured that nephrologists and PCPs were incorporated as core team members. Similarly, we relied upon the expertise of nephrology and primary care case managers to understand the less visible backoffice processes that govern consultation behavior. The involvement of the Chief of Medical Services as the project sponsor, was instrumental in marshalling the resources, time, and talent to ensure the success of the program.

Secondly, projects of this scale demand close coordination and proactive planning. The drafting and ratification of a project charter enabled team members to better understand their positions and responsibilities. Benchmarks for dashboard development and implementation permitted the team to remain committed to the task at hand. Beyond our team members, we coordinated closely with the individual clinics, advertising the availability of this service and sought feedback from PCPs at the forefront.

Thirdly, we utilized the Kano Model to understand users' needs with respect to dashboard design. The Kano Model is a systematic manner in which features can be categorized and prioritized for development. While our nephrologists prioritized certain features on their individual experiences, interests, and concerns, specialists from other fields may have other priorities. Therefore, using the Kano Model may help to bolster the flexibility of the intervention.

\section{Limitations}

Despite the potential of this dashboard system to engage in active surveillance of kidney disease in PCP clinics, there remain some important limitations.

First, it is unclear how generalizable and sustainable our findings are, since our project was implemented in 
only four clinics in the states of Iowa and Illinois. These clinics are predominantly rural in nature. As with all quality improvement projects, it is important to replicate findings in other settings, and we are currently pursuing this approach throughout the Iowa City Veterans Affairs Health Care System.

Secondly, our primary outcome of reducing the time to complete consultation was not met. The high variability is a major reason why we could not detect a change; additionally, the volume of new patients identified by the telenephrology dashboard system likely mitigated reductions in the time to complete consult requests. Yet there were other benefits of the telenephrology consult system, including improved workflow, early detection of certain kidney diseases, and savings in cost and time for Veterans. Therefore, even if consultations were not completed more rapidly, the intervention helped to reduce unwarranted waste for patients and practitioners.

Thirdly, the overarching larger impact on kidney health, i.e. progression to end-stage renal disease, has not yet been studied. We intend on continuing this project and collecting data to understand how better integration of nephrology into PCP clinics through the dashboard impacts the progression of chronic kidney disease and proteinuria over longer periods of time.

\section{Conclusions}

We were able to develop a system of actively monitoring kidney disease through a telenephrology dashboard system, and deploy it in 4 predominantly rural communitybased outpatient clinics. Although it did not result in decreased time to complete consultation, it enabled a larger volume of Veterans to receive specialist expertise within the context of their PCP clinics. The majority of nephrology consultations at our center are now completed electronically, and the majority of these consults are telenephrology consults. Veterans saved an average of $\$ 20.60$ to $\$ 63.90$ per trip to the nephrology clinic. The quality improvement team continues to adapt this intervention for wider scale implementation in all 10 community-based outpatient clinics in the Iowa City Veterans Affairs Health Care System.

\section{Supplementary information}

Supplementary information accompanies this paper at https://doi.org/10. 1186/s12882-020-02077-0.

Additional file 1. Current State Maps.

Additional file 2. Dashboard Questionnaire.

Additional file 3. Raw Data.

\section{Abbreviations}

CBOC: Community-based outpatient clinics; CVT: Clinical Video Telehealth DMAIC: Define-Measure-Analyze-Improve-Control; eGFR: Estimated glomerular filtration rate; PCP: Primary care provider; PDSA: Plan-Do-StudyAct; SBP: Systolic blood pressure; VA: Veterans Affairs

Acknowledgements

Danny Cox, PA-C, Mike Hackmann, MD, and Tabitha Beardsley, RN.

\section{Authors' contributions}

MS and MLS collected, analyzed and interpreted the data for quality improvement; MS, MLS, and BK were major contributors in writing the manuscript. $\mathrm{AO}, \mathrm{KP}$, and $\mathrm{BD}$ provided oversight in analyzing and interpreting the data. GB designed the dashboard implemented in this project. AT and NN collected data. All authors read and approved the final manuscript.

\section{Funding}

This project was funded by the Office of Rural Health, Veterans Affairs Health Care System.

\section{Availability of data and materials}

All data generated or analysed during this study are included in this published article and its supplementary information files.

\section{Ethics approval and consent to participate}

This manuscript reports data from a retrospective analysis of a quality improvement project. The project was submitted to the Institutional Review Board at the lowa City Veterans Affairs Health Care System and waived the need for consent. The study was determined exempt under the provisions of 45 CFR 46 Section 101(b) as per the United States Health Insurance

Portability and Accountability Act.

\section{Consent for publication}

Not applicable.

\section{Competing interests}

Bradley S. Dixon serves on a Data Safety \& Monitoring Board for a clinical trial for Humacyte, Inc.

\section{Author details}

${ }^{1}$ Division of Nephrology, University of lowa Hospitals and Clinics, 200 Hawkins Drive, lowa City, IA 52245, USA. ${ }^{2}$ lowa City Veterans Affairs Health Care System, lowa City, USA. ${ }^{3}$ Division of Immunology, University of lowa Hospitals and Clinics, lowa City, USA. ${ }^{4}$ Division of Internal Medicine, University of lowa Hospitals and Clinics, lowa City, USA

Received: 30 March 2020 Accepted: 23 September 2020

Published online: 06 October 2020

\section{References}

1. Fried LF, Palevsky PM. Decreasing prevalence of chronic kidney disease in the United States: a cause for optimism. Ann Intern Med. 2016;165(7):521-2.

2. Honeycutt AA, Segel JE, Zhuo $X$, et al. Medical costs of CKD in the Medicare population. J Am Soc Nephrol. 2013;24(9):1478-83.

3. Yarnoff BO, Hoerger TJ, Simpson SK, et al. The cost-effectiveness of using chronic kidney disease risk scores to screen for early-stage chronic kidney disease. BMC Nephrol. 2017 Mar 13;18(1):85.

4. Haley WE, Beckrich AL, Sayre J, et al. Improving care coordination between nephrology and primary care: a quality improvement initiative using the renal physicians association toolkit. Am J Kidney Dis. 2015;65(1):67-79. https://doi.org/10.1053/j.ajkd.2014.06.031.

5. Sharif MU, Elsayed ME, Stack AG. The global nephrology workforce: emerging threats and potential solutions! Clin Kidney J. 2016;9(1):11-22. https://doi.org/10.1093/ckj/sfv111.

6. Mottes TA, Goldstein SL, Basu RK. Process based quality improvement using a continuous renal replacement therapy dashboard. BMC Nephrol. 2019; 20(1):17. Published 2019 Jan 11. https://doi.org/10.1186/s12882-018-1195-8.

7. Dowding $D$, Randell $R$, Gardner $P$, et al. Dashboards for improving patient care: review of the literature. Int J Med Inform. 2015:84(2):87-100.

8. Randell R, Alvarado N, McVey $L$, et al. Requirements for a quality dashboard: Lessons from National Clinical Audits. AMIA Annu Symp Proc. 2020;2019: 735-44 Published 2020 Mar 4.

9. US Department of Veterans Affairs, and Veterans Health Administration. "lowa City VA Health Care System." About the lowa City VA Health Care 
System - lowa City VA Health Care System, https://www.iowacity.va.gov/ about/index.asp

10. Sloan T, Fitzgerald A, Hayes KJ, Radnor Z, Robinson S, Sohal A. Lean in healthcare-- history and recent developments. J Health Organ Manag. 2014; 28(2):130-4. https://doi.org/10.1108/JHOM-04-2014-0064.

11. Girdler SJ, Glezos CD, Link TM, et al. The science of quality improvement JBJS Rev. 2016;4(8):01874474-201608000-00002. https://doi.org/10.2106/JBJS. RW.15.00094.

12. Bellamkonda VR, Kumar R, Scanlan-Hanson LN, et al. Pilot study of Kano "attractive quality" techniques to identify change in emergency department patient experience. Ann Emerg Med. 2016 Nov;68(5):553-61.

13. Manns B, Hemmelgarn B, Tonelli M, et al. The cost of Care for People with Chronic Kidney Disease. Can J Kidney Health Dis. 2019;4.

14. Liu HH, Zhao S. Savings opportunity from improved CKD care management. J Am Soc Nephrol. 2018;29(11):2612-5.

15. Pizer SD, Prentice JC. What are the consequences of waiting for health care in the veteran population? J Gen Intern Med. 2011;26(Suppl 2):676-82.

16. Roubicek C, Brunet $P$, Huiart $L$, et al. Timing of nephrology referral: influence on mortality and morbidity. Am J Kidney Dis. 2000;36(1):35-41.

\section{Publisher's Note}

Springer Nature remains neutral with regard to jurisdictional claims in published maps and institutional affiliations.

Ready to submit your research? Choose BMC and benefit from:

- fast, convenient online submission

- thorough peer review by experienced researchers in your field

- rapid publication on acceptance

- support for research data, including large and complex data types

- gold Open Access which fosters wider collaboration and increased citations

- maximum visibility for your research: over $100 \mathrm{M}$ website views per year

At BMC, research is always in progress.

Learn more biomedcentral.com/submissions 